\title{
AMENORRHOEIC ATHLETES: AT RISK OF DEVELOPING OSTEOPOROSIS?
}

\author{
Janet MCARTHUR, MD \\ Department of Endocrinology, St. Bartholomew's Hospital, \\ West Smithfield, London EC1A
}

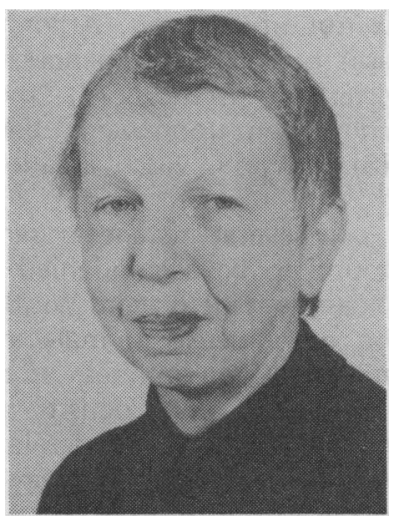

Janet McArthur
The growing involvement of women in sports, while enhancing general physical fitness, is being parallelled by an increasing incidence of medical complications. Among these are menstrual disorders, including a delay in the onset of menstruation, oligo- or amenorrhoea, and inadequacy of progesterone secretion during the luteal phase of the cycle. At first, only sporadic accounts of such disturbances appeared, suggesting that pre-existing functional derangements of cyclicity were likely to be responsible. However, the sheer volume of clinical reports now casts doubt on this view, as does a recent prospective study, in which a high proportion of women with previously normal cyclicity were observed to develop menstrual dysfunction while engaging in a graded exercise programme (Bullen et al, 1984).

Physiological interpretation is complicated by the fact that clinically similar disorders of menstruation are frequent accompaniments of weight loss and emotional stress, both of which occur often in subjects undergoing physical training and athletic competition. However, in a sports setting, exertion per se appears to be a significant component of a multifactorial process. Thus: (1) the menarche has been observed to occur promptly during injury- or vacation-related suspensions of exercise in ballet dancers studiously avoiding a concomitant increase in body weight (Warren, 1980), and (2) menstrual dysfunction, while more frequent in women permitted to lose weight during participation in a graded exercise programme than in those who maintained their weight, was a common occurrence in both groups (Bullen et al, 1984).

The pathogenesis of the exercise-associated menstrual disorders is not yet understood. Menstrual rhythmicity is known to depend upon an exquisitely programmed stimulation of ovarian steroid secretion by pulsatile release of the pituitary gonadotrophic hormones, folliclestimulating hormone (FSH) and luteinising hormone (LH). Pituitary secretion, in turn, reflects episodic stimulation by the hypothalamic gonadotrophin-releasing hormone (GnRH), which may be activated by a neural oscillator. A variety of neural and hormonal inputs influences the synthesis and release of $\mathrm{GnRH}$ and the pituitary response. Disturbances in gonadotrophic pulsatility are reflected in aberrations of menstrual cyclicity and, if sufficiently severe and prolonged, in its suspension.

Exercise delivers a strong stimulus to the endocrine system, evoking a complex pattern of changes in the circulating levels of many hormones. Concentrations of plasma insulin fall, while those of $\mathrm{ACTH}, \beta$-endorphin, met-enkephalin, growth hormone, prolactin, glucagon, catecholamines, melatonin and prostaglandins rise. The pertinence of these changes to the clinical disorders? of reproduction is uncertain. However, it is of interest that the administration of $\mathrm{ACTH}, \beta$-endorphin, prolactin and melatonin to experimental animals can delay sexual maturation, impair oestrous cyclicity and blight luteal function. The repetition of exercise tends to dampen the acute rise in hormonal levels, which is virtually extinguished in the case of certain hormones (e.g., metenkephalin) but apparently is better maintained for others (e.g., $\beta$-endorphin). Tonic elevations of the abovementioned hormones have not been detected in the body fluids of women athletes. However, a persistent depression of circulating levels of the reproductive hormones (oestrogens, progesterone, LH and, to a lesser extent, of FSH) is characteristic of the exercise-induced hypogonadism.

Clinical speculation regarding organs that might be affected unfavourably by prolonged stimulation by low levels of oestrogen in the absence of progesterone has, until recently, centred on the endometrium and breast. However, current research is focussing attention upon bone as a possible target of interaction between the sex steroid hormones and exercise stress.

Physical exertion exerts a major influence upon bone mass and upon the remodelling of bone. Immobilisation results in bone loss and activity in bone restitution. The manner in which muscular activity induces these effects 
is not understood. Among the mechanisms postulated are; (1) neural influences, perhaps mediated by piezoelectric currents, (2) mechanical stress and strain consequent upon weight bearing and muscle tension, and (3) changes in vascularisation and blood flow.

In several instances, participation in sports has been found to be accompanied by increased bone mass. For example, Nilsson and Westlin (1971) noted the femur to be more dense in male athletes than in healthy agematched non-athletes, as measured by photon absorption, with greater density in the leg of preference. Jones et al (1977) observed relative humeral hypertrophy in roentgenograms of the playing arm of professional tennis players of both sexes.

Hypo-oestrogenism, an important factor among several known to play a role in the genesis of postmenopausal osteoporosis, also occurs in amenorrhoeic athletes. Therefore, the outcome of attempts to prevent bone attrition in women following the climacteric by means of exercise regimens is of interest in a sports context. From measurements of total body calcium, Aloia et al (1978) concluded that a mild exercise programme (i.e., 1 hour/day, 3 days/week) retarded the development of osteoporosis in women who were approximately 5 years past the menopause. Smith et al (1981) found that a light to moderate physical activity programme, one designed around a chair, increased the bone mineral content of the radius by $2 \%$, as measured by photon absorption, in 69-95 year old women in a nursing home. Krolner et al (1983) noted that an 8 months' moderate training load increased the mineral content of the lumbar spine, but not that of the forearm, as measured by dual photon absorptiometry, in healthy 50-73 year old women who had previously sustained a Colles' fracture.

That bone attrition rather than accretion may result from vigorous exercise by amenorrhoeic athletes is indicated by recent study of Drinkwater et al (1984). These investigators compared the vertebral mineral density of 14 amenorrhoeic athletes $(11$ runners and 3 crew members) with that of 14 eumenorrhoeic athletes. The latter were selected from a pool to match the amenorrhoeic women with respect to sport, age, weight, height and the frequency and duration of daily training sessions, in that order of priority. A satisfactory match was achieved for all physical characteristics, including body composition (as determined by hydrostatic weighing), a property not included in the original profile. The athletic history of the two groups differed significantly, the mean weekly mileage of the eumenorrhoeic group being $\mathbf{2 4 . 9}$ and that of the amenorrhoeic group 41.8 miles. The dietary intake of total calories and of fat by the amenorrhoeic athletes was lower than that of the eumenorrhoeic subjects but the difference did not quite achieve statistical significance, while calcium intakes were similar. Hormonal assays for plasma oestradiol, progesterone, testosterone and prolactin concentrations were performed on four samples of blood obtained at intervals. These revealed significantly higher oestradiol, prolactin and progesterone levels in the eumenorrhoeic women, and equivalent testosterone concentrations in the two groups.

Measurements of regional bone mass were made by single photon absorptiometry for the appendicular skeleton (the distal radius of the non-dominant arm at two sites) and by dual photon absorption for the axial skeleton (vertebral bodies and disc interspaces of the individual vertebrae $L_{1}$ through $\left.L_{4}\right)$. No differences were found between the amenorrhoeic and eumenorrhoeic groups with respect to the mineral content of the radius, but that of the vertebrae was significantly lower in athletes belonging to the amenorrhoeic group, and was lower in runners than in crew members.

Comparison of these results with population norms revealed close correspondence of the radial measurements without regard to the menstrual status of the athletes. Likewise, there was good agreement between vertebral mineral density in the eumenorrhoeic athletes and that predicted from a normal population by means of an age age-based regression equation. However, the mean vertebral mineral density in the amenorrhoeic group corresponded to that of women $\mathbf{5 1 . 2}$ years of age. In two athletes, the vertebral mineral density fell below the fracture threshold of $0.965 \mathrm{~g} / \mathrm{cm}^{2}$, as defined by Riggs et al (1982).

As Drinkwater et al (1984) point out, confirmation of these findings is required, as is extension to other skeletal areas, in particular to those subjected to repeated mechanical stresses in specific sports. Elucidation of the mechanisms responsible for the hypo-estrogenism and menstrual disturbances is of scientific and potential clinical importance. Ultimately, such research should lead to prophylactic measures enabling women to benefit from vigorous participation in sports, without compromise of bone integrity or other deleterious consequences of hypo-oestrogen ism.

\section{References}

Aloia, J. F., Cohn, S. H., Ostuni, J. A., Cane, R. and Ellis, K. 1978 "Prevention of involutional bone loss by exercise". Ann.Int. Med. 89: 356-358.

Bullen, B. A., Skrinar, G. S., Beitins, I. Z., von Mering, G. Turnbull, B. A. and McArthur, J. W., 1984 "Induction of menstrual disorders in untrained women by strenuous exercise". Submitted for publication.

Drinkwater, B. L., Nilson, K., Chesnut, C. H. 3rd, Bremner W. J., Shainholtz, S. and Southworth, M. B., 1984 "Bone mineral content of amenorrhoeic and eumenorrhoeic athletes". New Eng.J.Med. 311: 277-281.

Jones, H. H., Priest, J. D., Hayes, W. C., Tichenor, C. C. and Nagel, D. A., 1977 "Humeral hypertrophy in response to exercise". J.Bone and Joint Surg. 59A: 204-8.

Krolner, B., Toft, B., Nielsen, S. P. and Tondevold, E., 1983 "Physical exercise as prophylaxis against involutional vertebral bone loss: a controlled trial". Clin.Sci. 64: 541-6.

Nilsson, B. E. and Westlin, N. E., 1971 "Bone density in athletes". Clin.Orthopaed. and Related Research 77: 179-182. 
Riggs, B. L., Wahner, H. W., Seeman, E., Offord, K. P., Dunn, W. L., Mazess, R. B., Johnson, K. A. and Melton, L." J. 3rd, 1982 "Changes in bone mineral density of the proximal femur and spine with aging: differences between the postmenopausal and senile osteoporosis syndromes". J.Clin. Invest. 70: 716-23.
Smith, E. L. Jr., Reddan, W. and Smith, P. E., 1981 "Physical activity and calcium modalities for bone mineral increase in aged women". Med.Sci. Sports Exerc. 13: 60-64.

Warren, M. P., 1980 "The effects of exercise on pubertal progression and reproductive function in girls". J.Clin. Endocrinol. Metab. 51: 1150-57.

\section{THE 5th SCOTTISH RESIDENTIAL COURSE}

School of Further Education, Jordanhill College

in association with the University of Strathclyde

1st-6th September, 1985

A comprehensive introductory course for medical practitioners, chartered physiotherapists and appropriately qualified sports scientists and physical educationists.

A one-week residential course is organised in association with the British Association of Sport and Medicine (Scotland), Jordanhill College of Education and the University of Strathclyde. The course is fully recognised by the Federation Internationale de Medecine Sportive whose representative monitor contributes to the course. Appropriately qualified medical practitioners attending should qualify under Section 63 for reimbursement of subsistence and travel expenses only as the course has been recognised in the past by the West of Scotland Committee for Post Graduate Medical Education.

The campus at Jordanhill has the largest College of Education in Scotland. The Stow Building was opened in 1921 and since then numerous extensions have been made including two swimming pools. A notable feature of the College is that it came to embrace two national institutions, the Scottish School of Physical Education and the School of Further Education.

The College stands in its own grounds and there are extensive playing areas and gymnasia.

Visitors should note that soft shoes (not black soled) must be worn by all persons entering games halls and gymnasia for demonstrations or participation. Sports facilities can be booked but in fairness the course programme is fairly intensive although many previous students have enjoyed running off their extra calories at breaks in the timetable.

This course will be followed directly by the Edinburgh course (9th-13th September). Previous students have proceeded directly to second course and found them complementary and very useful.

\section{SPORTS MEDICINE \\ 9th-13th September, 1985, Edinburgh \\ This course follows directly on 5th Scottish Residential Course recognised by FIMS}

This intensive course has been designed primarily for general practitioners actively involved in sports medicine. A limited number of places will also be available for qualified physiotherapists, coaches or doctors in other branches of medicine. It will be held in the Dunfermline College of Physical Education in Edinburgh, where residential accommodation will be available.

Course fee $£ 70$ (Section 63 approval for general practitioners). Accommodation will be charged separately. 